\title{
Food Supplements Were Applied to the Mitochondrial Capacity of Retinal Cells and Oxidative Phosphorylation of Adenosine Triphosphate (ATP) Synthesis
}

\author{
Shun-Chieh Yang ${ }^{1}$, Chi-Tang Tu ${ }^{1}$, Han-Chung Cheng ${ }^{1}$, Ying-Chieh Lai ${ }^{2}$, Shou-Jen Lan ${ }^{2,3, *}$ \\ ${ }^{1}$ Taiwan Mitochondrion Applied Technology Co..Ltd, Taiwan \\ ${ }^{2}$ Department of Healthcare Administration, Asia University, Taiwan \\ ${ }^{3}$ Department of Medical Research, China Medical University Hospital, China Medical University, Taichung, Taiwan \\ *Corresponding author: shoujenlan@gmail.com; sjlan@asia.edu.tw
}

\begin{abstract}
The retina consists of many different cells, the most important of which are retinal cells. Retinal cells have a lot of mitochondria. The mitochondria in retinal cells provide the energy of retinal cell activity, including the energy required to convert light into nerve signals. However, when the sun enters the eye and is irradiated on the retina, the high-energy ultraviolet light in the solar energy causes the mitochondria in the retinal cells and retinal cells to produce free radicals. These free radicals are detrimental to retinal cells and mitochondrial intima. Long-term accumulation, in addition to free radicals directly to the damage caused by retinal cells, the serious damage to the mitochondrial intima can also cause mitochondrial decomposition, and then lead to retinal cell apoptosis. This study discloses an eye care method comprising the provision of Phyllanthus emblica extract for the use of retinal cells in the late stage of ultraviolet or ultraviolet irradiation to obtain mitochondria in retinal cells of chlorophyll extract for oxidative phosphoric acid (ATP) synthesis Higher than the mitochondria, without Phyllanthus emblica extract of retinal cells, and with triphosphate (ATP) for phosphorylation. According to the above method, the supply of Phyllanthus emblica extract retinal cells protects the inner membrane of mitochondria in retinal cells, thereby delaying the decomposition time of mitochondria, adding Phyllanthus emblica extract can also reduce the free radical content of retinal cells such as bamboo leaf extract can slow Mitotic decomposition caused by the rate of apoptosis and can reduce the effectiveness of retinal cells due to excessive free radical content and damage to protect retinal cells to achieve eye care.
\end{abstract}

Keywords: Phyllanthus emblicas, retinal cell, mitochondria, ATP

Cite This Article: Shun-Chieh Yang, Chi-Tang Tu, Han-Chung Cheng, Ying-Chieh Lai, and Shou-Jen Lan, "Food Supplements Were Applied to the Mitochondrial Capacity of Retinal Cells and Oxidative Phosphorylation of Adenosine Triphosphate (ATP) Synthesis." Journal of Food and Nutrition Research, vol. 5, no. 9 (2017): 636-641. doi: 10.12691/jfnr-5-9-2.

\section{Introduction}

Exposure to ultraviolet (UV) A and short-wavelength visible radiation, from environment, may induce the production of reactive oxygen species (ROS) and result in oxidative damage to RPE cells $[1,2,3]$. Oxidative injury and functional impairment may act an early and important role in the development of age-related macular degeneration (AMD) $[2,4,5,6]$, Previous studies have indicated that damage to RPE through photochemical mechanisms by free radical reactions is driven by photo-excited, endogenous chromophores through the cornea and lens [2]. As we age, the yellow pigment accumulates; however, oxidative damage increases, antioxidant capacity decreases and the efficiency of self-repairing systems deteriorate during the aging process. Loss of RPE cells, cataract formation, and retinal dysfunction may lead to visual impairment.
Phyllanthus emblica extract can slow down the rate of cell apoptosis and trigger the rate of apoptosis, and can reduce the retinal cells due to excessive free radical content and damage, to protect the retinal cells, and then achieve the effect of the eye method of care [6].

In this study, the method of eye care revealed that the Phyllanthus emblica extract to retinal cells protects the endometrium of mitochondria in retinal cells [1], thereby delaying the time of disintegration of granules, and the addition of Phyllanthus emblica extract can also reduce Free Radical Content in Retinal Cells [2,5].

\section{Materials and Methods}

\subsection{Emblica Extracts}

The extraction of emblica officinalis was emblica fruit, useing $5 \%$ of sodium chloride aqueous solution, the extract was purified by filtration to obtain the emblica 
extract used in this study. The emblica extract can be subjected to a drying procedure using Spray dry or vacuum drying to obtain an easily preserved emblica extract powder.

\subsection{HPLC of Emblica Extracts}

HPLC developing solvent, Ethyl acetate-acetic acid-formic acid-Water (100:11:11:27); detection, absorption/quenching mode, A max $254 \mathrm{~nm}$ ] and characteristic peak signal at 1.620 minutes, 2.148 minutes, 3.265 minutes and 4.370 minutes (Figure 1). It containing $35 \%$ to $55 \%$ by weight of Emblicanin-A with Emblicanin-B mixture, $4 \%$ to $15 \%$ by weight of Punigluconin, $10 \%$ to $20 \%$ by weight of Pedunculagin , $5 \%$ to $15 \%$ by weight Rutin.

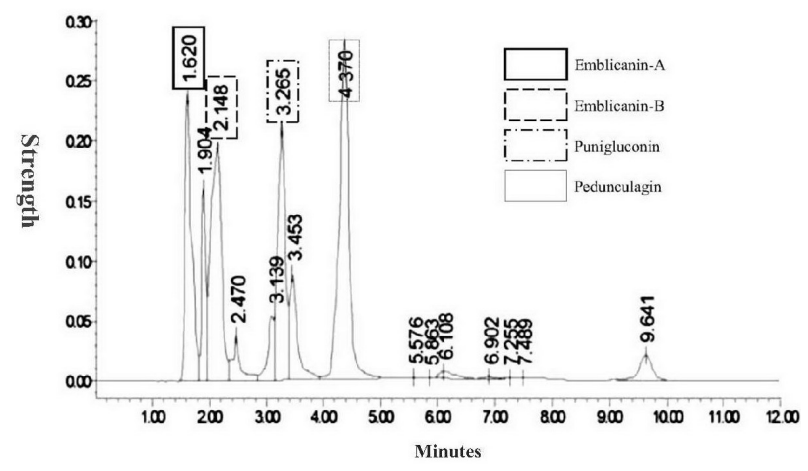

Figure 1. The high performance HPLC Chromatogram of emblica extract

The structural formula of Emblicanin-A (2,3-di-O-galloyl4,6-(S)-hexahydroxydiphenoyl-2-keto-glucono-lactone)<smiles>O=C(OC1=C2OC(=O)C(c3cc(O)c(O)c(O)c3)OC2C(=O)OC2COC(=O)c3cc(O)c(O)c(O)c3-c3c(cc(O)c(O)c3O)C(=O)OC12)c1cc(O)c(O)c(O)c1</smiles>

The structural formula of Emblicanin -B (2,3,4,6-bis(S)-hexahydroxydiphenoyl-2-keto-glucono-lactone)

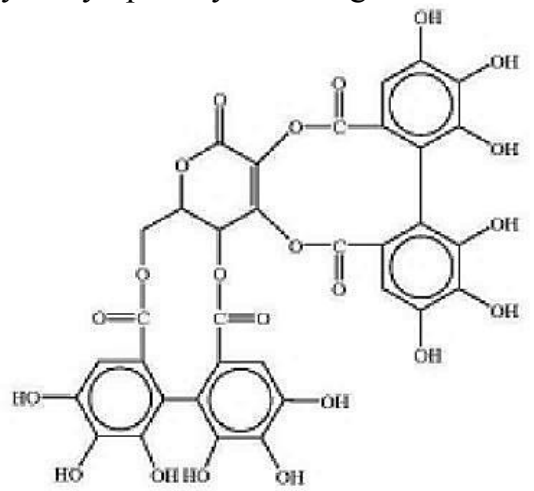

The structural formula of Ponigluconin (2,3-di-Ogalloyl-4,6-(S)-hexahydroxydiphenoyl gluconic acid)<smiles>O=C(O)c1cc(O)c(O)c(O)c1-c1c(C(=O)OC(C(O)C(=O)O)C(O)C(O)C(=O)O)cc(O)c(O)c1O</smiles>

The structural formula of Pedunculagin (2,3,4,6-bis-(S)hexahydroxydiphenoyl -D-glucose)<smiles>O=C(OCC1OC(O)c2oc(=O)c3cc(O)c(O)c(O)c3c3c(O)c(O)c(O)cc3c(=O)oc2C1OC(=O)c1cc(O)c(O)c2c1OCCCC2)c1cc(O)c(O)c(O)c1O</smiles>

The structural formula of Rutin tetrahydroxyflavono-1,3-O-rhamnoglucoside)<smiles>CCOc1c(-c2ccc(O)c(O)c2)oc2cc(O)cc(O)c2c1=O</smiles>

\subsection{Cell culture}

Adult human retinal pigment epithelial cells (ARPE19) were obtained from Bioresource collection and research center (BCRC) in Taiwan and were cultured in Dulbecco's Modified Eagle's Medium/Nutrient Mixture F-12 (DMEM/F12) supplemented with $10 \%$ fetal calf serum (GibcoBRL, Invitrogen Life Technologies, Carlsbad, CA, USA), 100 units $/ \mathrm{mL}$ penicillin, and $100 \mu \mathrm{g} / \mathrm{mL}$ streptomycin (Sigma Chemical Co.) in a humidified incubator at $37^{\circ} \mathrm{C}$ with $5 \% \mathrm{CO}_{2}$.

\subsection{Cell Proliferation Assay}

To determine the proliferation of (bilberry or amla or composition) on the ARPE19 cells, $2 \times 10^{3}$ cells in single cell suspensions were seeded in individual wells of 96-well plates and incubated for $24 \mathrm{~h}$ at $37^{\circ} \mathrm{C}$ prior to 
exposure to Phyllanthus emblica the indicated concentrations for $24 \mathrm{~h}$ before UVA radiation for $4 \mathrm{~h}$. UVA irradiation using a Bio-Sun system illuminator from VilberLourmat (VilberLourmat Deutschland GmbH, Germany). UVA radiation was supplied by a closely spaced array of four UVA lamps that delivered uniform irradiation at a distance of $10 \mathrm{~cm}$. The UVA lamps emit ultraviolet rays between 355 and $375 \mathrm{~nm}$, with peak luminosity at $365 \mathrm{~nm}$. It took approximately $74-80 \mathrm{~min}$ to attain (irradiance: 4.2-4.5 $\mathrm{mW} / \mathrm{cm}^{2}$ ) the target UVA irradiation dose, $20 \mathrm{~J} / \mathrm{cm}^{2}$. Alamar blue solution was added to each well followed by incubation for $4 \mathrm{~h}$ at $37^{\circ} \mathrm{C}$ prior to removing the culture medium. Cell proliferation was determined by measuring the absorbance at $530 / 595 \mathrm{~nm}$. The cell proliferation for each group was calculated as a percentage of that of the control group.

\subsection{Measurement of Reactive Oxygen Species}

The levels of intracellular reactive oxygen species (ROS) were measured using the fluorescent probe 5-(and6)-carboxy-2', 7'-dichlorohydrofluorescein diacetate $\left(\mathrm{H}_{2}-\right.$ DCFDA). ARPE19 cells, $2 \times 10^{3}$ cells in single cell suspensions were seeded in individual wells of 96-well plates and incubated for $24 \mathrm{~h}$ at $37^{\circ} \mathrm{C}$ prior to exposure to Phyllanthus emblica the indicated concentrations for $24 \mathrm{~h}$ before UVA irradiation for $2 \mathrm{~h}$. ARPE19 cells were incubated with $10 \mu \mathrm{M} \mathrm{H}$-DCFDA for 15 minutes at $37^{\circ} \mathrm{C}$ and then washed in serum-free minimum essential medium (DMEM). Cells were observed under a fluorescence microscope and photographed.

\subsection{Measurement of Cellular Oxygen Consumption Rate (OCR)}

ARPE19 cells were plated at $8 \times 10^{4}$ cells/well in gelatin-coated XF 24-well cell culture microplates (Seahorse Bioscience), ARPE19 cell was incubated in a pre-warmed unbuffered DMEM medium (DMEM containing $2 \mathrm{mM}$ GlutaMAX, $1 \mathrm{mM}$ sodium pyruvate, $1.85 \mathrm{~g} \mathrm{l}-1 \mathrm{NaCl}$ and $25 \mathrm{mM}$ glucose) for $1 \mathrm{~h}$. The oxygen consumption rate was measured by the XF24 extracellular flux analyser (Seahorse Biosciences). Mitochondrial biogenesis was profiled by injecting perturbation drugs, $0.5 \mu \mathrm{M}$ oligomycin, $2 \mu \mathrm{M}$ FCCP and $0.5 \mu \mathrm{M}$ antimycin $\mathrm{A}$, in succession. OCR was determined by plotting the oxygen tension and acidification of the medium in the chamber as a function of time and normalized by protein concentration (picomoles per minute per milligram), respectively.

\section{Results}

\subsection{Protection by Phyllanthus Emblica Extract against UVA Induced Decrease in Cell Viability}

Cell viability assay showed that the viability of ARPE19 cells dropped after UVA exposure the decrease was reduced by pretreating the cells with Phyllanthus emblica extract at the concentrations of 250 and $500 \mathrm{ug} / \mathrm{ml}$ (Figure 2). Particularly at the concentration of $250 \mathrm{ug} / \mathrm{ml}$, the survival rate of ARPE-19 cells pretreated with Phyllanthus emblica extract was significantly higher $(p<0.01)$ than those without treatment; approximately $30 \%$ of pretreated cells remained viable upon UVA exposure. These observations indicate that resveratrol is effective in the prevention of UVA-induced ARPE19 cell damage.

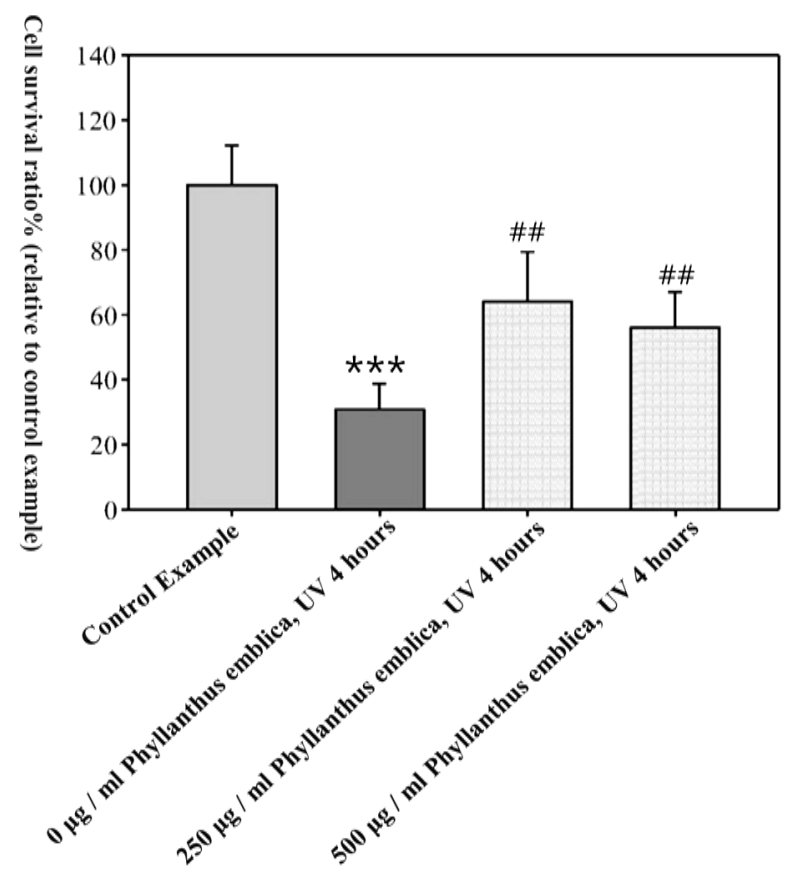

Figure 2. Phyllanthus emblica extract protect cell alive from UVA irradiation $4 \mathrm{~h}$. $* * *$ indicates that it is significantlydifferent from UVA-exposed cells to control group $(p<0.001)$, \#\# indicates that it significantlydifferent from Phyllanthus emblica extract group toUVAexposed group $(p<0.05)$

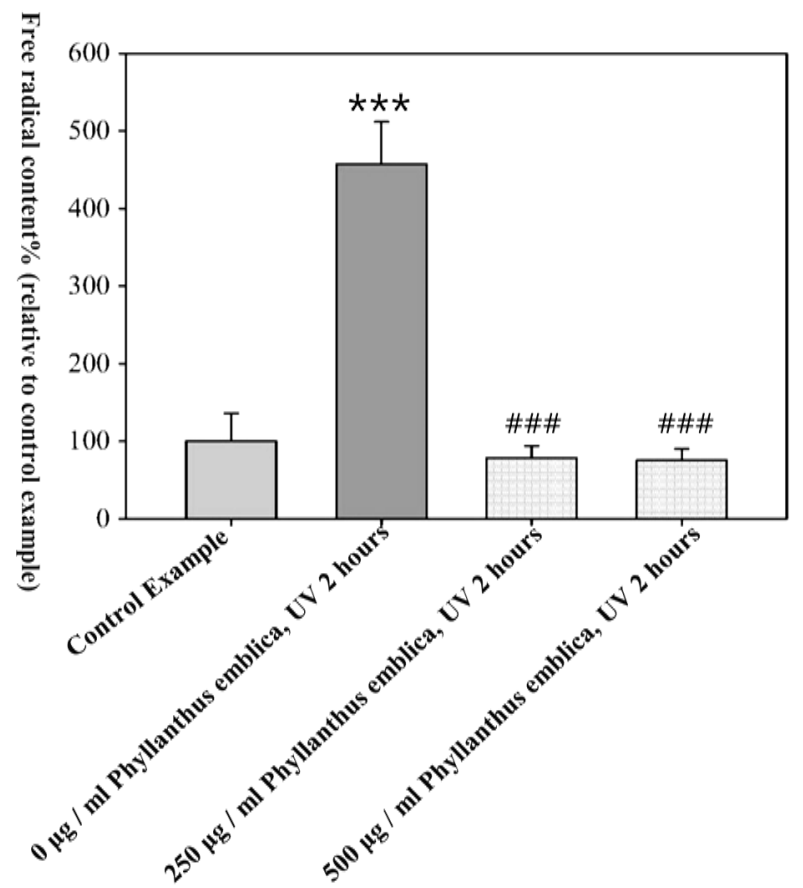

Figure 3. Phyllanthus emblica extract decrease ROS level from UVA irradiation $2 \mathrm{~h}$. ${ }^{* * *}$ indicates that it is significantlydifferent from UVAexposed cells to control group $(p<0.001)$, \#\#\# indicates that it is significantlydifferent from Phyllanthus emblica extract group toUVAexposed group $(p<0.001)$ 


\subsection{Protection by Phyllanthus Emblica Extract against UVA Induced ROS in ARPE-19 Cell}

Treatment of ARPE cells with UVA exposure 2 hours increased the intracellular accumulation of ROS (Figure 3) compared with untreated cells. Phyllanthus emblica extract attenuated the ROS accumulation in a concentration-dependent manner with maximal effect seen at $500 \mathrm{ug} / \mathrm{ml}$ concentration. This concentration of Phyllanthus emblica extract was used for all subsequent experiments. At $250 \mathrm{ug} / \mathrm{ml}$ concentration, inhibited ROS accumulation in the cells by 4 fold compared with UVA only group (Figure 3). Pretreatment with Phyllanthus emblica extract reversed the protective effects of UVA radiation.

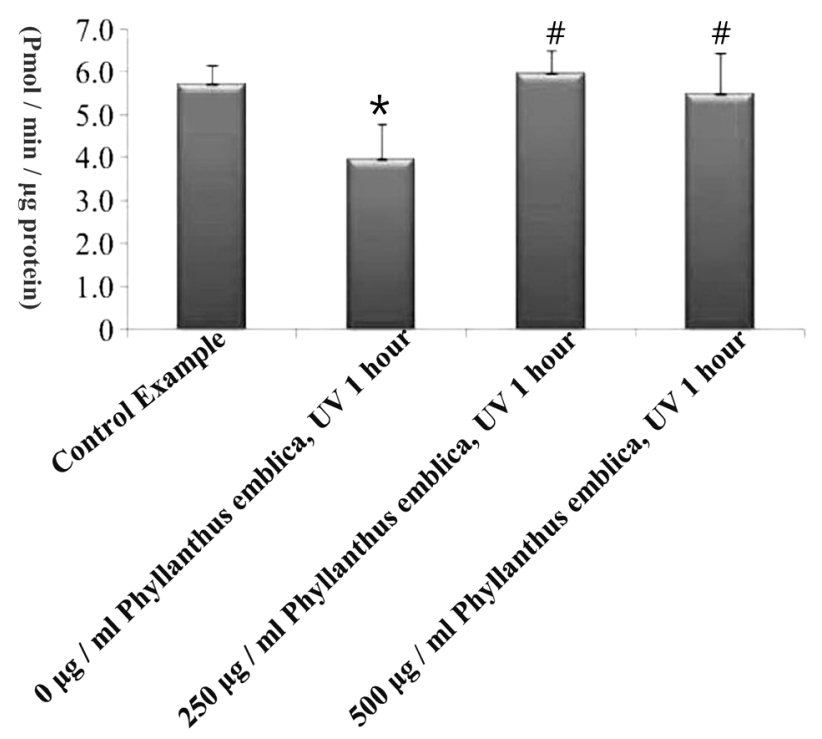

Figure 4. Phyllanthus emblica extract increase ATP level from UVA irradiation $1 \mathrm{~h} . *$ indicates that it is significantlydifferent from UVAexposed cells to control group $(p<0.05)$, \# indicates that it is significantlydifferent from Phyllanthus emblica extract group toUVAexposed group $(p<0.05)$

\subsection{Effect of Phyllanthus Emblica Extract on Mitochondrial Energy Metabolism}

To characterize the effect of Phyllanthus emblica extract on mitochondrial metabolism, we measured the OCR in ARPE-19 cells using Seahorse Bioscience technology. At 24 hours after incubation, 250 and 500 $\mathrm{ug} / \mathrm{ml}$ Phyllanthus emblica extract resulted in a significant increase in ATP production relative to that in the UVA group cells $(40 \%, \mathrm{P}<0.05)$ (Figure 4$)$. The complex $\mathrm{V}$ inhibitor oligomycin $(0.5 \mathrm{uM})$ was used to estimate the proportion of the basal OCR coupled to ATP synthesis. Following the addition of oligomycin, the percentage declines in OCR in the Phyllanthus emblica extract treated cells were indicating that ATP production was significantly affected by Phyllanthus emblica extract treatment. The mitochondrial uncoupling agent FCCP $(2 \mathrm{uM})$ was subsequently used to further determine maximal respiratory capacity. After the addition of FCCP, OCR showed a substantially greater increase in ARPE-19 cells treated with Phyllanthus emblica extract, by incubation, 250 and $500 \mathrm{ug} / \mathrm{ml}$ Phyllanthus emblica extract resulted in a significant decrease in hydrogen leakage relative to that in the UVA group cells (30 40\%, $\mathrm{P}<0.05$ ) (Figure 5) The last step of the experiments was application of the complex III inhibitor antimycin $(0.5 \mathrm{uM})$ to inhibit the electron transport to complex V. This treatment resulted in a profound suppression of the OCR, and the residual oxygen consumption was accounted for by nonmitochondrial oxygen-consuming pathways. In 24 hours after incubation, 250 and $500 \mathrm{ug} / \mathrm{ml}$ Phyllanthus emblica extract resulted in a no significant effect in maximum oxygen consumption relative to that in the UVA group cells (Figure 6). Suggesting that Phyllanthus emblica extract act the ATP production and hydrogen leakage but not maximum oxygen consumption in ARPE-19 cell mitochondrial energy metabolism.

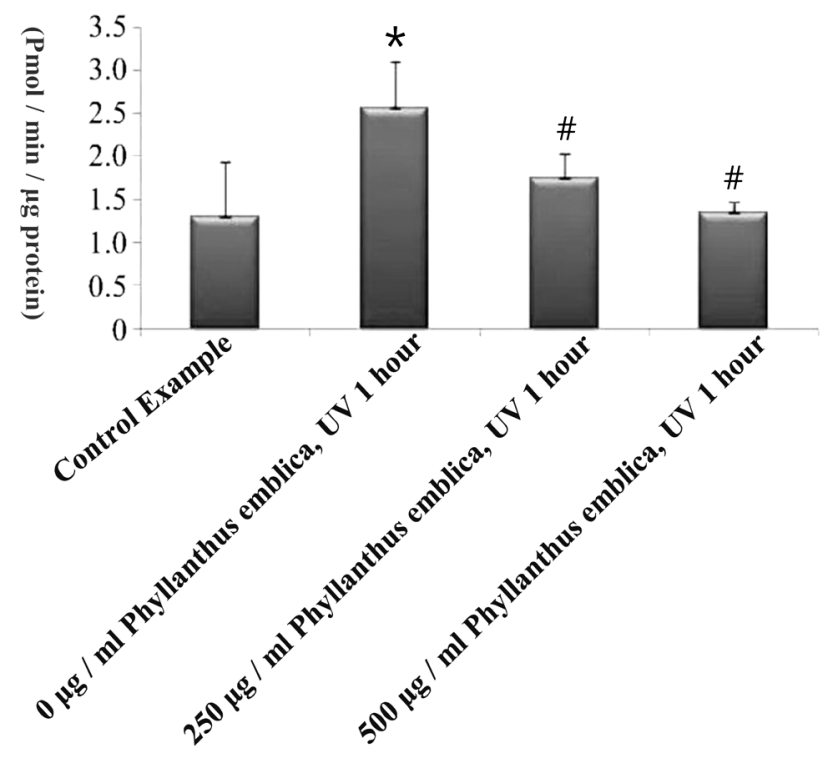

Figure 5. Phyllanthus emblica extract drease hydrogen leakage from UVA irradiation $1 \mathrm{~h} . *$ indicates that it is significantlydifferent from UVA-exposed cells to control group $(p<0.05$ ), \# indicates that it significantlydifferent from Phyllanthus emblica extract group toUVAexposed group $(p<0.05)$

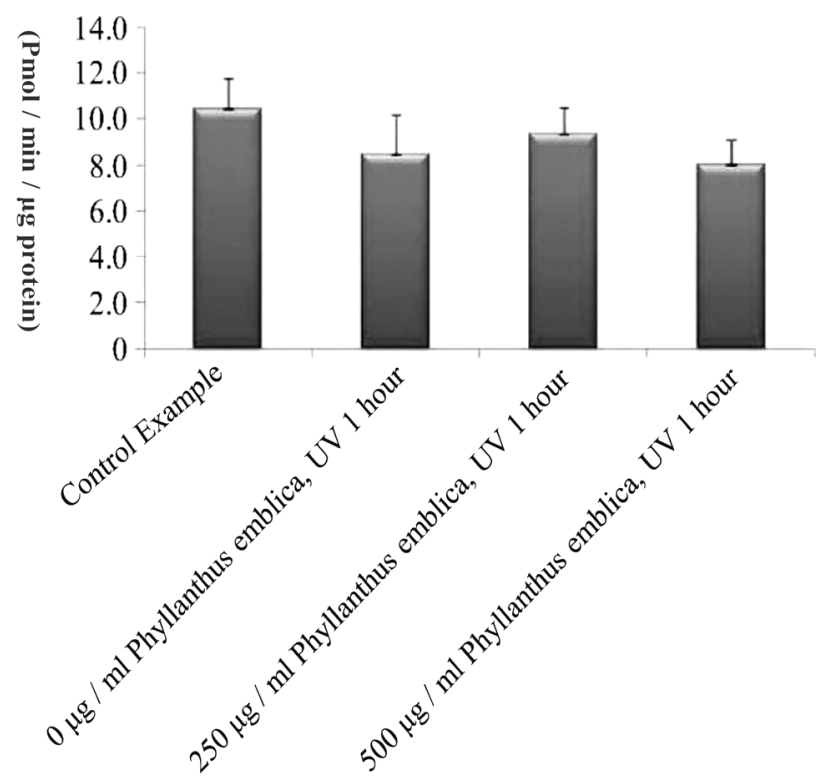

Figure 6. Phyllanthus emblica extract was noneffect on maximum oxygen consumption from UVA irradiation $1 \mathrm{~h}$ 


\section{Discussion}

The progress of science and technology brings people into contact with electronic products every day. Electronic products emitted the light causes damage to the retina by free radical attacks, which is a common phenomenon [3,7].

In the past, people often use vitamin A and lutein as eye care products [8]. Our study focused on photoreceptor retinal cells with different light waves to test their mitochondrial responses $[9,10]$. We found that mitochondria in retinal cells produce large amounts of free radicals and attack retinal cells under different light waves, and when we use different concentrations of Gandhi extract it significantly reduces free radical production and reduces damage to retinal cells. Study the use of Seahorse XFe24 Extracellular Flux Analyzer measurement principle, which is our research characteristics. First, detect the basal oxygen consumption of the cells in the wells. Then, the addition of the triphosphate glucoside synthetase inhibitor to inhibit the mitochondria to produce the triphosphate, where the reduced oxygen consumption is the mitochondrial oxidative phosphorylation reaction to synthesize the oxygen consumption of the ribosine triphosphate, that is, the mitochondria, of the basic oxygen consumption (Basal Respiration). The triphosphate synthetase inhibitor is, for example, oligomycin. Then, by adding an appropriate concentration of the anti-coupling agent, the mitochondria are allowed idling to limit the maximum oxygen consumption capacity of the mitochondria (Maximal Respiration) without destroying the electron transport chain of the mitochondrial inner membrane [4]. The anti-coupling agent is Carbonylcyanide-4-(trifluoromethoxy) phenylhydrazone (FCCP). Finally, the addition of an electron transport chain inhibitor has completely shut down the oxygen consumption of the mitochondria, thereby confirming the measured background value, i.e., non-mitochondrial response. The electron transfer chain inhibitor is, for example, a combination of Rotenone and Antimycin A.

The basic oxygen consumption of the mitochondria is equal to the basal oxygen consumption of the cells minus the non-mitochondrial oxygen consumption. The oxygen consumption of the mitochondria minus the amount of oxygen consumed by the synthesis of the triphosphate is equivalent to overcoming the oxygen consumption of the Proton Leakage.

The maximum oxygen consumption of mitochondria minus mitochondrial basal oxygen consumption equals mitochondrial pre-storage oxygen consumption (Spare Respiratory Capacity). Mitochondrial triphosphate Synergistic efficiency (Coupling Efficiency) is equal to the synthesis of lysine triphosphate oxygen consumption divided by mitochondria based oxygen consumption [11].

The above-mentioned study revealed the method of eye care, applying Phyllanthus emblica extract to retinal cells to protect the endometrium of mitochondria in retinal cells, thereby delaying the time of disintegration of mitochondria. The addition of Phyllanthus emblica extract can reduce retinal cells In the free radical content. in this way, Phyllanthus emblica extract can slow down the rate of apoptosis caused by mitochondrial disintegration, and can reduce the retinal cells due to excessive free radical content and damage, and then to achieve effectiveness of protection of retinal cells, and to achieve eye care effect $[7,12,13]$.

In order to facilitate ingestion of the Phyllanthus emblica extract by orally, the Phyllanthus emblica extract can be prepared, for example, in the form of liquid, solid, granular, powdered, paste or gelatinous extract. Phyllanthus emblica extract products can be used as an additive enhance the flavor making it easy to eat [13].

\section{Conclusion}

In this study, the retina cells of Phyllanthus emblica extract can protect the endometrium of retinal cells [5], thereby delaying the time of disintegration of mitochondria, and the addition of Phyllanthus emblica extract can reduce the free radical content in retinal cells[14]. In this way, Phyllanthus emblica extract can slow down the rate of apoptosis caused by mitochondrial disintegration, and can reduce the retinal cells due to excessive free radical content and damage, and supply the required effectiveness of protection of retinal cells, and to achieve the eye care effect $[2,15,16]$.

\section{Acknowledgements}

This study was supported by grants from Taiwan Mitochondrion Applied Technology Co., Ltd. This study did not receive any specific grant from funding agencies in the public, commercial, or not-for-profit sectors.

\section{Compliance with Ethical Standars}

Competing interests material supporting this study was provided by the Taiwan mitochondrion Ltd. .None of the sponsors (list companies) had any role in the design or execution of this study. None of the authors have any financial interest in any of the products or devices mentioned in this manuscript or any competing fiancial interests.

\section{References}

[1] Chan, C.M., et al., Protective effects of resveratrol against UVA-induced damage in ARPE19 cells. Int J Mol Sci, 2015. 16(3): p. $5789-802$.

[2] Bruce A. Berkowitz, 2 Bryce X. Bredell,1 Christopher Davis,1 Marijana Samardzija,3 and a.R.R. Christian Grimm, Measuring In Vivo Free Radical Production by the Outer Retina. Investigative Ophthalmology \& Visual Science, 2015.

[3] Kataoka, T., Study of antioxidative effects and anti-inflammatory effects in mice due to low-dose $\mathrm{X}$-irradiation or radon inhalation. $\mathrm{J}$ Radiat Res, 2013. 54(4): p. 587-96.

[4] Bergman, O. and D. Ben-Shachar, Mitochondrial Oxidative Phosphorylation System (OXPHOS) Deficits in Schizophrenia: Possible Interactions with Cellular Processes. Can J Psychiatry, 2016. 61(8): p. 457-69.

[5] Bruce A. Berkowitz, Timothy S. Kern, David Bissig, Priya Patel, Ankit Bhatia, and a. R.R. Vladimir J. Kefalov, Systemic Retinaldehyde Treatment Corrects Retinal Oxidative Stress, Rod Dysfunction, and Impaired VisualPerformance in Diabetic Mice. The Association for Research in Vision and Ophthalmology, Inc. iovs.arvojournals.org, 2015. 
[6] den Hollander, A.I., et al., Lighting a candle in the dark: advances in genetics and gene therapy of recessive retinal dystrophies. J Clin Invest, 2010. 120(9): p. 3042-53.

[7] Hoon, M., et al., Functional architecture of the retina: development and disease. Prog Retin Eye Res, 2014. 42: p. 44-84.

[8] Kohno, H., et al., Photoreceptor proteins initiate microglial activation via Toll-like receptor 4 in retinal degeneration mediated by all-trans-retinal. J Biol Chem, 2013. 288(21): p. 15326-41.

[9] Narsing Adupa Rao, M., ROLE OF OXYGEN FREE RADICALS IN RETINAL DAMAGE ASSOCIATED WITH EXPERIMENTAL UVEITIS*. TR. AM. OPHTH. Soc. , 1990.

[10] Perusek, L. and T. Maeda, Vitamin A derivatives as treatment options for retinal degenerative diseases. Nutrients, 2013. 5(7): p. 2646-66.

[11] Phaniendra, A., D.B. Jestadi, and L. Periyasamy, Free radicals: properties, sources, targets, and their implication in various diseases. Indian J Clin Biochem, 2015. 30(1): p. 11-26.
[12] Seiji Hayashi, S.-i.I., Guey-Shuang Wu, Won R Wee, Narsing A Rao, and P.J. McDonnell, Oxygen free radical damage in the cornea after excimer laser therapy. British Journal of Ophthalmology 1996: p. 141-144.

[13] Tang, P.H., et al., Effective and sustained delivery of hydrophobic retinoids to photoreceptors. Invest Ophthalmol Vis Sci, 2010. 51(11): p. 5958-64.

[14] Usharani, P., N. Fatima, and N. Muralidhar, Effects of Phyllanthus emblica extract on endothelial dysfunction and biomarkers of oxidative stress in patients with type 2 diabetes mellitus: a randomized, double-blind, controlled study. Diabetes Metab Syndr Obes, 2013. 6: p. 275-84.

[15] V. Lobo, A.P., [...], and N. Chandra, Free radicals, antioxidants and functional foods_Impact on human health. Pharmacognosy Reviews, 2010: p. 118-126.

[16] Xinxian Zhu, J.W., Polyphenol extract of Phyllanthus emblica (PEEP) induces inhibition of cell proliferation and triggers apoptosis in cervical cancer cells. Zhu et al. European Journal of Medical Research, 2013. 